\title{
Effect of Ti: Sapphire and Nd: YAG Lasers on Shear Bond Strength at the Zirconia - Veneering Ceramic Juncture
}

\author{
Anamika Abraham ${ }^{1 *(\infty}$, Deshraj Jain $^{2 \oplus}$, Alka Gupta $^{3}$, J A Chakera $^{4^{(}}$ \\ ${ }^{1}$ Department of Prosthodontics, Government College of Dentistry, Indore, Madhya Pradesh, India \\ ${ }^{2}$ Principal \& Head, Department of Prosthodontics, Government College of Dentistry, Indore, Madhya Pradesh, \\ India \\ ${ }^{3}$ Department of Prosthodontics, Government College of Dentistry, Indore, Madhya Pradesh, India \\ ${ }^{4}$ Laser Plasma Division, Raja Ramanna Centre for Advanced Technology (RRCAT), \\ Indore, Madhya Pradesh, India
}

\section{*Correspondence to Anamika Abraham, M.D.S. Department of Prosthodontics, Government College of Dentistry, Indore, Madhya Pradesh, India. \\ Email dranamikaabraham@ rediffmail.com}

\section{Received: March 5, 2020} Accepted: September 11, 2021 Published online November 7 , 2021

\begin{abstract}
Introduction: This study was conducted to assess the impact of nanosecond and femtosecond lasers on shear bond strength at the zirconia - veneering ceramic juncture.

Materials and Methods: The first 60 samples of partially sintered zirconia cylindrical discs measuring $7 \mathrm{~mm}$ diameter and $4 \mathrm{~mm}$ height were milled and sintered. Then they were randomly divided into three groups namely group $C$ (control, $n=10)$, group $N(N d$ : YAG laser, $n=10)$, and group $T$ (Ti: sapphire laser $n=40$ ) which was further divided based on the duration of laser irradiation, into 4 subgroups $(n=10$ each) which were 30 seconds, 1 minute, 2 minutes and 3 minutes. Surface treatment was done on sintered zirconia discs based on the group. Following the treatment, the discs were ultrasonically cleaned followed by liner application (IPS Emax Zirliner, Ivoclar-Vivadent) and veneer ceramic layering (IPS e.max Ceram, Ivoclar-Vivadent) of $1.5 \mathrm{~mm}$ height. Each sample underwent shear stress in the universal test machine on the mounting jig, and bond strength was evaluated. Data were assessed using ANOVA followed by Tukey's post hoc multiple comparison analyses.

Results: According to one-way ANOVA, there was a significant difference in shear bond strength between the groups. Tukey's post hoc pair wise comparison test showed a significant difference $(P$ value $=0.001$ ) in shear bond strength of all pairs except group $C$ and group $N$. The results of repeated measures, ANOVA (related and dependent groups) and Tukey's multiple pair wise comparison test showed that there was a significant difference $(P$ value $=0.001)$ in shear bond strength at 30 seconds and all other groups.

Conclusion: Ti: sapphire laser irradiation for 30 seconds can be used as potential surface treatment to increase shear bond strength at the zirconia-veneering ceramic juncture.

Keywords: Shear strength; Lasers; Zirconium; Femtosecond laser; Nd: YAG laser.
\end{abstract}

\section{Introduction}

In this era of cosmetic dentistry, zirconia based dental ceramics have emerged as a leading biomaterial for implants and fixed dental prostheses. Yttrium-partially stabilized, tetragonal zirconia polycrystal (Y-TZP) has excellent mechanical properties namely high flexural strength (900-1200 MPa), elastic modulus of $201 \mathrm{GPa}$, fracture toughness $\left(7-10 \mathrm{MPa} / \mathrm{m}^{2}\right)$, chemical durability, excellent biocompatibility, good optical behavior, low bacterial adhesion, low thermal conductivity, and high radiopacity. ${ }^{1}$ Zirconia can be used as either a monolithic restoration or a substructure/core of bi-layer restoration.
Zirconia is inherently opaque; therefore, for optimum aesthetics and to match the translucency of natural teeth, a layer of translucent glass ceramic is veneered over a zirconia core. The veneering ceramic is secured onto the zirconia substructure by one of the two methods: the layering technique and the press technique. ${ }^{2}$ An effective bond is entirely dependent on the micromechanical coupling between the veneering ceramic and zirconia. Contrary to Y-TZP, the veneering ceramic does not have high fracture toughness and the weak bond at the zirconia-veneering ceramic juncture leads to the chipping of veneering ceramics. ${ }^{3}$ The strength of ceramic 
restoration is reliant on the weakest factor, either the coreveneer juncture or the veneer layer. ${ }^{4}$

Various studies have been conducted on the coreveneer bond strength by improving bonding potential, increasing wet-ability and increasing surface area. The use of laser irradiation for zirconia surface texturing has gained research interest. ${ }^{5}$ Researchers have investigated the effect of $\mathrm{CO}_{2}$, Nd:YAG (neodymium-doped yttrium aluminum garnet), Er: YAG (erbium-doped yttrium aluminium garnet laser), Er: YSGG (Erbium-doped yttrium, scandium, gallium and garnet) and titanium (Ti): sapphire lasers on the zirconia surface..$^{6-8}$ These lasers are used for porcelain etching by creating microcavities using superficial heat. Nd: YAG causes morphologic changes by superficial melting and random recrystallisation of the porcelain surface. ${ }^{9}$ Further studies are needed to ameliorate bond quality between the zirconia core-veneer juncture with special emphasis on the use of shorter pulse duration lasers. The effect of the Ti: sapphire laser on the zirconia-veneering ceramic juncture has never been evaluated and compared until now. ${ }^{10}$ The Ti: sapphire laser ( $\left.\mathrm{Ti}: \mathrm{Al}_{2} \mathrm{O}_{3}\right)$ is a tunable solid - state laser which emits red and near -infrared light in the wavelength range of 650 to $1180 \mathrm{~nm} .{ }^{11}$ It is an ultrafast femtosecond laser with high peak intensity causing material ionization and ejection without heat transfer to the environment. ${ }^{12}$

In this study, transformation-toughened zirconia was used as a substructure and the nano-fluorapatite glass veneering ceramic (IPS e.max Ceram) $)^{13}$ was used as the veneering ceramic. The effect of the Q-Switched $\mathrm{Nd}$ : YAG and Ti: sapphire laser as a mode of surface texturing on post sintered zirconia and its efficacy on shear bond strength at the zirconia - veneering ceramic juncture were evaluated.

This comparative in-vitro study was conducted to assess the impact of nanosecond and femtosecond laser surface treatment on shear bond strength at the zirconia- veneering ceramic juncture and compare with the conventional method as control group without laser surface treatment.

\section{Materials and Methods}

A total of 60 samples in the form of a disc were prepared from a partially sintered zirconia blank (NexxZr, Sagemax, Ivoclar Vivadent, USA) of $98 \mathrm{~mm}$ diameter $\times 10 \mathrm{~mm}$ height by CAD/CAM technology. A stereolithographic (STL) model of the required dimension of $7 \mathrm{~mm}$ diameter by $4 \mathrm{~mm}$ length was designed for the study and uploaded on exocad ${ }^{\oplus}$ software (Germany). The software calculates the percentage of linear shrinkage and performs computer-controlled milling to create a zirconia disc of enlarged size. Computer-aided Milling was done (Roland Milling Machine). The connectors were removed using a micro-motor hand piece and a straight fissure tungsten carbide bur. As per the manufacturer's instructions, the milled zirconia discs were sintered in a Nabertherm zirconia sintering furnace at 1550 degrees Celsius for 8 hours' duration. The chemical composition of ceramics utilized in the study is depicted in Table 1. Zirconia core discs were randomly allocated into three groups, namely Group C (control $n=10)$, group $\mathrm{N}(\mathrm{Nd}$ : YAG Laser $n=10$ ) and group T (Ti sapphire Laser $n=40$ ). Group $\mathrm{T}$ was further subdivided into 4 subgroups based on the duration of laser exposure at 30 seconds, 1 minute, 2 minute and 3 minutes (each subgroup had 10 samples).

\section{Laser Surface Treatment}

Zirconia discs of Group $\mathrm{N}$ and $\mathrm{T}$ were coated with a layer of graphite using a soft-lead pencil because of the increased absorption of the laser beam on the darker surface (Figure 1).

The following LASER parameters were used in the study:

Group N:

Table 1. Chemical Composition of Ceramic Materials Used in This Study

\begin{tabular}{|c|c|c|c|c|c|c|}
\hline Material & Type & Chemical Composition & $\operatorname{Tg}$ & Poisson & $\mathbf{E}$ & CTE \\
\hline NexxZrT & $\begin{array}{l}\text { Yttrium- stabilized } \\
\text { zirconium oxide }\end{array}$ & $\begin{array}{l}\mathrm{ZrO} 2 \geq 89 \%, \mathrm{Y} 2 \mathrm{O} 34-6 \%, \mathrm{HfO} 2 \leq \\
5 \%, \mathrm{Al} 2 \mathrm{O} 3<1 \% \text {, and other oxides } \\
\leq 0.2 \% \text {, }\end{array}$ & 1700 & 0.3 & 210 & $\begin{array}{l}10.1 \leq \mathrm{CTE} \\
\quad \leq 11.1\end{array}$ \\
\hline IPS e.max® Ceram & $\begin{array}{l}\text { Low-fusing nano- } \\
\text { fluorapatite glass } \\
\text { ceramic }\end{array}$ & $\begin{array}{l}\mathrm{SiO} 260-65 \%, \mathrm{Al} 2 \mathrm{O} 38-12 \% \text {, } \\
\mathrm{K} 2 \mathrm{O} 6-8 \%, \mathrm{Na} 2 \mathrm{O} 6-9 \%, \mathrm{ZnO} \\
2-3 \% \text {; } \mathrm{CaO}, \mathrm{P} 2 \mathrm{O} 5 \text { and F } 2-6 \% \text {, } \\
\text { other oxides } 2-8.5 \% \text {, pigments } \\
0.1-1.5 \%\end{array}$ & 495 & 0.24 & 60 & 9.8 \\
\hline IPS Emax® Zirliner & $\begin{array}{l}\text { Nano-fluorapatite } \\
\text { glass powder liquid } \\
\text { all-round }\end{array}$ & $\begin{array}{l}\text { Powder: } \mathrm{SiO} 250-60 \% \text {; } \mathrm{Al} 2 \mathrm{O} 3 \\
16-22 \% \text {; } \mathrm{K} 2 \mathrm{O} 4-8 \% \text {; Na2O } \\
6-11 \%, \mathrm{ZrO} 21.5-3 \%, \mathrm{CaO} 1.5- \\
\text { 4\%, P2O5 0.8-2\%, F 0.2-1.5\%; } \\
\text { other oxides } 0.1-1 \% \text { Liquid: } \\
\text { water }>94 \% \text {, butandiol < } 5 \% \text {, Zinc } \\
\text { chloride }<1 \%\end{array}$ & 645 & 0.22 & 65 & 10.4 \\
\hline
\end{tabular}

Note: $\left(\%\right.$ by weight), glass transitional temperature $\left(\mathrm{Tg},{ }^{\circ} \mathrm{C}\right)$, elastic modulus $(\mathrm{E}, \mathrm{GPa})$, coefficient of thermal expansion $\left[\mathrm{CTE} ;\left(\times 10^{-6} /{ }^{\circ} \mathrm{C}\right)\right]$. 


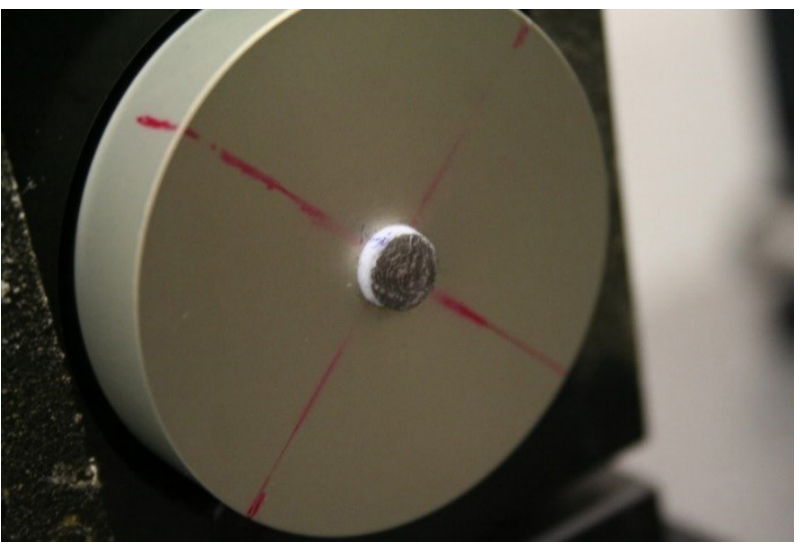

Figure 1. Graphite Coated Zirconia Disc.

Laser medium - Neodymium-doped yttrium aluminum garnet Crystal

Wavelength $\lambda$ - $1064 \mathrm{~nm}$

Mode of operation - Dual pulsed Q- Switched mode

Optical Delivery - Articulated Arm

Beam size - $7 \mathrm{~mm}$

Spot size - $7 \mathrm{~mm}$ diameter

Energy density (Fluence) - $260 \mathrm{~mJ} / \mathrm{cm}^{2}$

Pulse duration - 5-10 nanoseconds

Frequency - $10 \mathrm{~Hz}$

Duration of exposure - 30 seconds

Scanned in non-contact mode

Absence of air or water cooling

Distance - $4 \mathrm{~mm}$

The relationship between power and pulse width of Q Switched Nd: YAG LASER is shown in Figure 2. LASER surface treatment was performed using Q Switched Nd: YAG laser from Lutronic Spectra (Figure 3).

Group T:

LASER Medium - Titanium sapphire crystal

Wavelength $\lambda-800 \mathrm{~nm}$

Mode of operation - Long pulsed mode

Bandwidth $(\Delta \lambda)-22 \mathrm{~nm}$

Pulse duration - 50 femtosecond

Laser energy - $6 \mathrm{~mJ}$

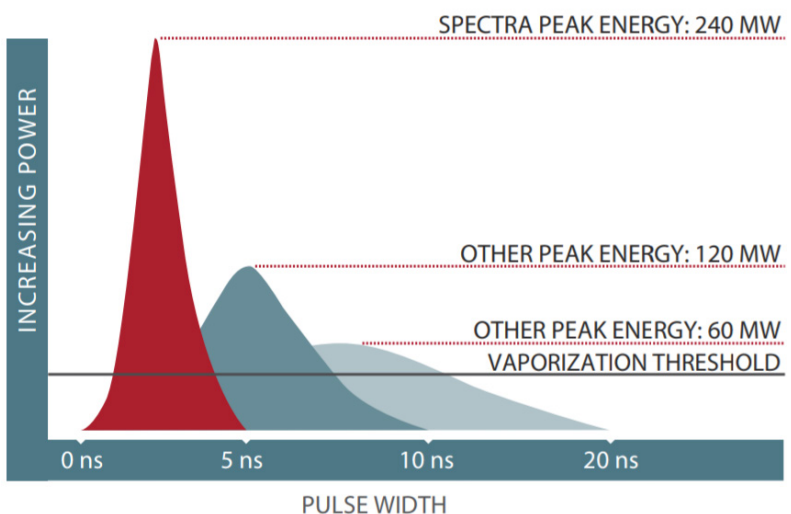

Figure 2. Graph Showing Relation Between Power and Pulse Width of Q Switched Nd: YAG.
Frequency - $1 \mathrm{kHz}$

Beam size - $18 \mathrm{~mm}$

Spot size - $7 \mathrm{~mm}$ diameter

Energy density (Fluence) - $12 \mathrm{~mJ} / \mathrm{cm}^{2}$

Scanned in non-contact mode

Absence of air or water cooling

Based on the time duration of laser exposure: Subgroup 30 seconds, subgroup 1 minute, subgroup 2 minutes, subgroup 3 minutes.

The laser system used here is a Ti: sapphire laser system from Coherent Quantronix -Integra-C system (HamdenCT-USA (Figure 4). It is a $\mathrm{KHz}$ system with the above parameters. A lens $(\mathrm{f}=50 \mathrm{~cm})$ was used to partially focalize the laser beam.

Control group: Specimens of this group were not subjected to LASER surface treatment.

\section{Liner Application}

All specimen were subjected to an ultrasonic cleaner for

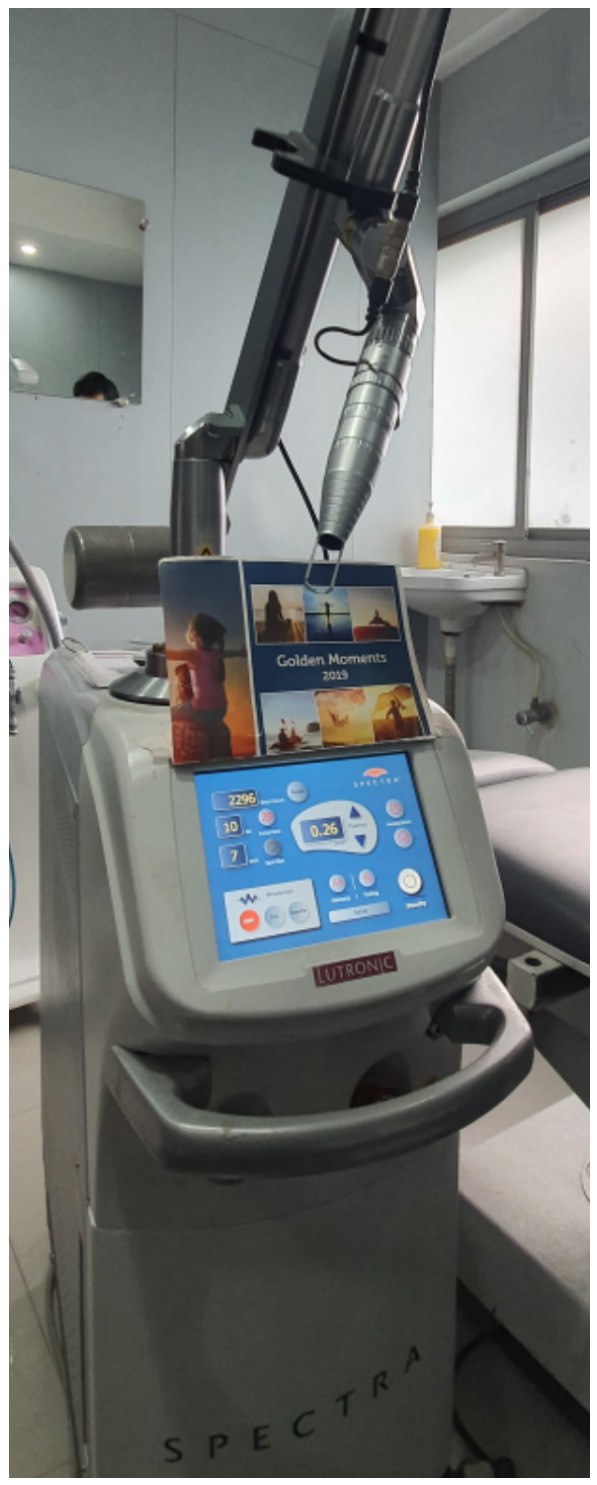

Figure 3. GNd: YAG Laser. 


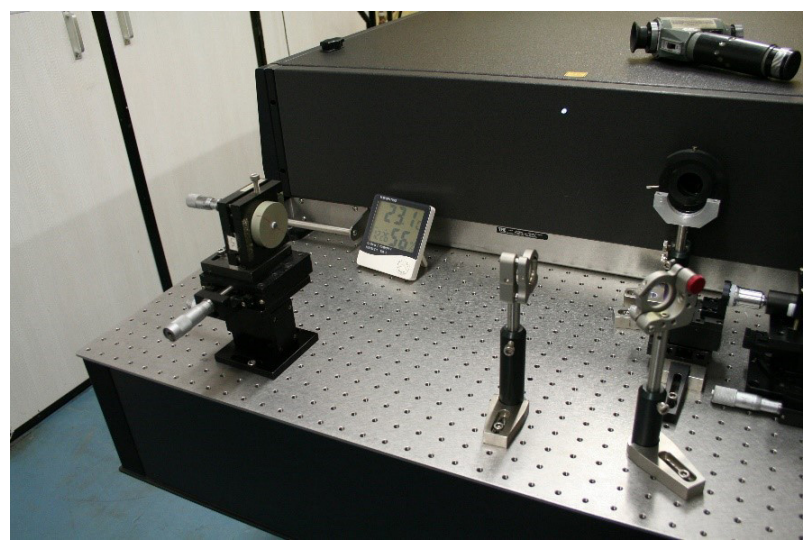

Figure 4. Ti Sapphire Laser.

3 minutes (APL ultrasonic cleaner CD-4800 PSI, Florida, USA). A coating of a liner (IPS e.max Zirliner, IvoclarVivadent Schaan, Liechtenstein, Germany) on zirconia discs was sintered in a furnace (Programmat ${ }^{\circledR}$ P3010, Ivoclar-Vivadent Schaan, Liechtenstein, Germany) to 0.1 mm thickness.

\section{Bonding With Veneer Ceramic}

In this study, IPS e.max Ceram which is a nano-fluorapatite glass ceramic is used as a veneering ceramic over zirconia core discs. The creamy consistency dentine ceramic (IPS e.max Ceram, Ivoclar-Vivadent) was layered, condensed, and sintered for no more than three times to derive the final dimension of $1.5 \mathrm{~mm}$ (Figure 5).

\section{Shear Bond Strength Testing}

Specimens were placed on a customized mounting-jig ${ }^{14}$ and underwent a shear bond strength test by subjecting to shearing force in a universal testing machine (Instron-5565, Norwood, MA, USA) (Figure 6). Loading was done at a crosshead speed of $1 \mathrm{~mm} / \mathrm{min}$ until failure. ${ }^{15}$ A shear load is a force that produces sliding failure on a subject that is parallel to the direction of the force and coplanar with material cross-section. In this study the force was directed at the zirconia - veneering ceramic juncture. The force that produces a bonding failure or de-lamination of veneering ceramic from zirconia was noted. The observed shear force values were evaluated using ANOVA followed by Tukey's post hoc multiple comparison analysis. The data were statistically analyzed using SPSS 15 statistical package. The test was carried out at the significance level of 0.05 .

\section{Results}

The descriptive statistics and one-way ANOVA to compare between the three groups are depicted in Table 2 which shows a significant difference in bond strength among the groups. As shown in Table 3, Tukey's pairwise comparison analyses depict a significant difference in shear bond strength of all pairs except the control group and $\mathrm{Nd}$ :

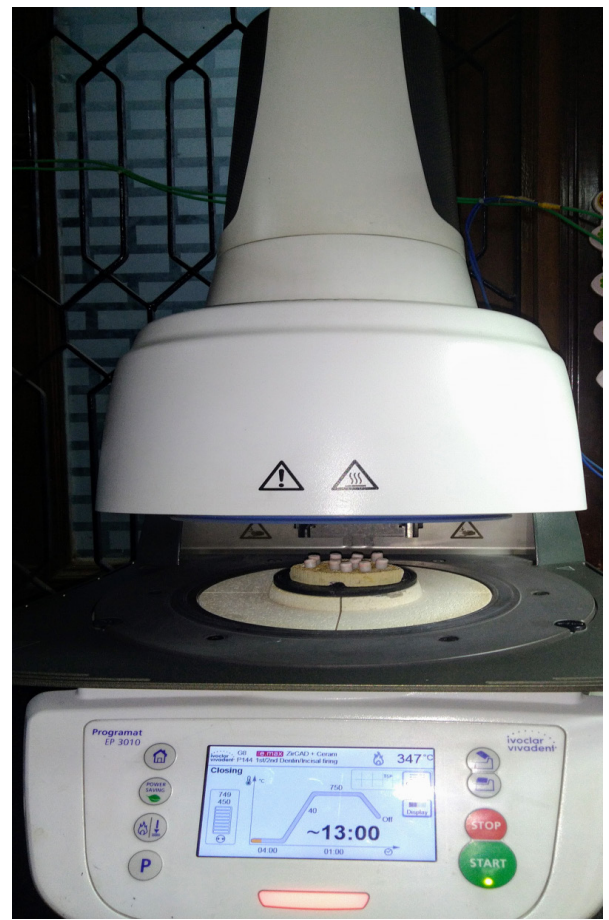

Figure 5. Veneer Ceramic Firing.

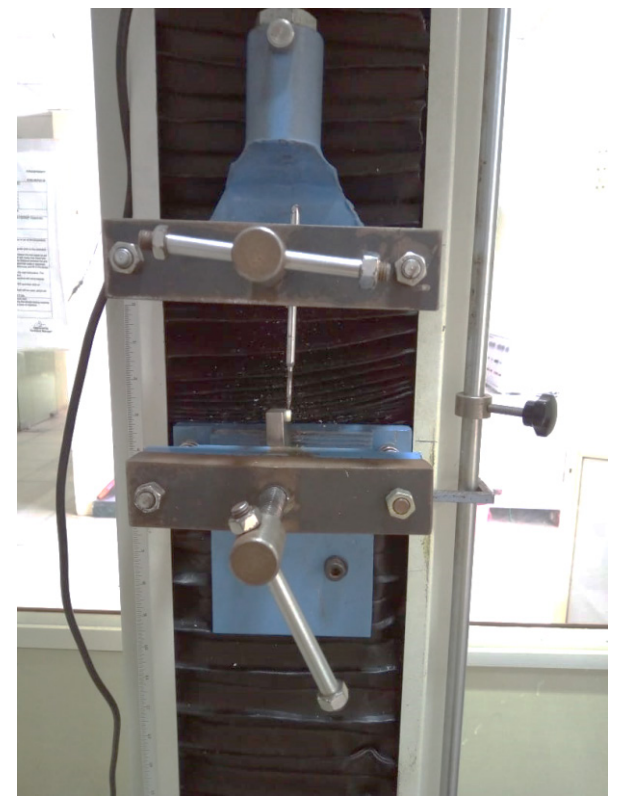

Figure 6. Shear Bond Strength Testing.

YAG. The repeated measures ANOVA test was performed among the subgroups of group T (Table 4). Tukey's post hoc pairwise multiple comparison analyses depict a significant difference between shear bond strength at 30 seconds and all the other groups (Table 5). Figure 7 denotes a graphical representation of the mean shear bond strength between group C (Control), group $\mathrm{N}$ (Nd: YAG), and group $\mathrm{T}$ (Ti: sapphire) at 30 seconds duration of laser exposure. The test shows that there is a highly significant difference $(P$ value $<0.001)$ in bond strength between the groups owing to the greater mean bond strength in laser- 
Table 2. Descriptive Statistics and One-Way ANOVA to Compare the Difference in Shear Bond Strength Between the Three Groups

\begin{tabular}{|c|c|c|c|c|c|c|c|}
\hline \multirow{2}{*}{ Group } & \multirow{2}{*}{ Mean } & \multirow{2}{*}{ SD } & \multirow{2}{*}{ Std. Error } & \multicolumn{2}{|c|}{$95 \% \mathrm{Cl}$ for Mean } & \multirow{2}{*}{$\mathbf{F}$} & \multirow{2}{*}{$P$ Value } \\
\hline & & & & Lower & Upper & & \\
\hline Control & 343.7000 & 107.202 & 33.900 & 267.01 & 420.38 & \multirow{3}{*}{51.92} & \multirow{3}{*}{0.001} \\
\hline NDYAG & 403.0000 & 66.2486 & 20.949 & 355.60 & 450.39 & & \\
\hline Ti Sapphire & 669.6000 & 39.1980 & 12.395 & 641.55 & 697.64 & & \\
\hline
\end{tabular}

Table 3. Tukey's Pairwise Comparison

\begin{tabular}{|c|c|c|c|c|c|}
\hline \multirow{2}{*}{ Group (I) } & \multirow{2}{*}{ (J) Group } & \multirow{2}{*}{ Mean Difference (I-J) } & \multicolumn{2}{|c|}{$95 \% \mathrm{Cl}$} & \multirow{2}{*}{$P$ Value } \\
\hline & & & Lower & Upper & \\
\hline \multirow{2}{*}{ Control } & NDYAG & -59.30000 & -143.789 & 25.1892 & 0.209 \\
\hline & Ti Sapphire & $-325.90000^{*}$ & -410.389 & -241.4108 & 0.000 \\
\hline \multirow{2}{*}{ NDYAG } & Control & 59.30000 & -25.1892 & 143.7892 & 0.209 \\
\hline & Ti Sapphire & $-266.60000^{*}$ & -351.089 & -182.1108 & 0.000 \\
\hline \multirow{2}{*}{ Ti Sapphire } & Control & $325.90000^{*}$ & 241.4108 & 410.3892 & 0.000 \\
\hline & NDYAG & $266.60000^{*}$ & 182.1108 & 351.0892 & 0.000 \\
\hline
\end{tabular}

Table 4. Repeated Measures ANOVA

\begin{tabular}{lccc}
\hline Subgroups & Mean & SD & $\boldsymbol{P}$ Value \\
\hline $30 \mathrm{~s}$ & 669.60 & 39.19807 & 0.001 \\
$1 \mathrm{~min}$ & 405.60 & 88.94842 & 0.001 \\
$2 \mathrm{~min}$ & 441.80 & 91.96956 & 0.001 \\
$3 \mathrm{~min}$ & 377.40 & 130.17441 & 0.001 \\
\hline
\end{tabular}

treated groups, especially group $\mathrm{T}$ for 30 -second duration, than that of the control group.

\section{Discussion}

Zirconia is chemically inert, and it is difficult to get an effective bond with veneering ceramics.

The rate of failure for zirconia-based restoration was notified at $36 \%$ due to chipping, whereas metal ceramic restoration accounted for $16 \% .{ }^{16}$ Various factors that affect the core-veneer bond are surface texture, wetting, coefficient of thermal expansion, presence of surface irregularity and the chemical interlinking of bonded materials. ${ }^{14}$

LASER is light amplification by stimulated emission of radiation. Dr. Georgios Siviloglou has defined LASER as "A finite-energy Airy Beam that can bend and travel without scattering"17. LASER is precise and has the power to heal, create and destroy. Laser treatment works in non-contact mode and renders high flexibility for improving the surface texture of biomaterials, without changes in biochemical characteristics. It demonstrates minimal damage to biomaterials and possesses a very high repeatability rate. ${ }^{18}$ High level laser output energy was reported to produce many micro-cracks and the deterioration of zirconia surface. ${ }^{8,9}$ Low output laser

Table 5. Tukey's Multiple Pairwise Comparison

\begin{tabular}{|c|c|c|c|c|c|c|}
\hline \multirow{2}{*}{ (I) Factor1 } & \multirow{2}{*}{ (J) Factor 1} & \multirow{2}{*}{$\begin{array}{c}\text { Mean Difference } \\
(\mathrm{I}-\mathrm{J})\end{array}$} & \multirow{2}{*}{ Std. Error } & \multicolumn{2}{|c|}{$95 \% \mathrm{Cl}$ for Difference ${ }^{\mathrm{b}}$} & \multirow{2}{*}{$P$ value } \\
\hline & & & & Lower & Upper & \\
\hline \multirow{3}{*}{$30 \mathrm{sec}$} & $1 \mathrm{~min}$ & $264.000^{*}$ & 32.577 & 154.404 & 373.596 & .000 \\
\hline & $2 \min$ & $227.800^{*}$ & 32.686 & 117.837 & 337.763 & .000 \\
\hline & $3 \mathrm{~min}$ & $292.200^{*}$ & 39.242 & 160.181 & 424.219 & .000 \\
\hline \multirow{3}{*}{$1 \mathrm{~min}$} & $30 \mathrm{~s}$ & $-264.000^{*}$ & 32.577 & -373.596 & -154.404 & .000 \\
\hline & $2 \min$ & -36.200 & 44.827 & -187.008 & 114.608 & 1.000 \\
\hline & $3 \mathrm{~min}$ & 28.200 & 60.747 & -176.165 & 232.565 & 1.000 \\
\hline \multirow{3}{*}{$2 \min$} & $30 \mathrm{~s}$ & $-227.800^{*}$ & 32.686 & -337.763 & -117.837 & .000 \\
\hline & $1 \mathrm{~min}$ & 36.200 & 44.827 & -114.608 & 187.008 & 1.000 \\
\hline & $3 \mathrm{~min}$ & 64.400 & 54.115 & -117.652 & 246.452 & 1.000 \\
\hline \multirow{3}{*}{$3 \mathrm{~min}$} & $30 \mathrm{~s}$ & $-292.200^{*}$ & 39.242 & -424.219 & -160.181 & .000 \\
\hline & $1 \mathrm{~min}$ & -28.200 & 60.747 & -232.565 & 176.165 & 1.000 \\
\hline & $2 \min$ & -64.400 & 54.115 & -246.452 & 117.652 & 1.000 \\
\hline
\end{tabular}




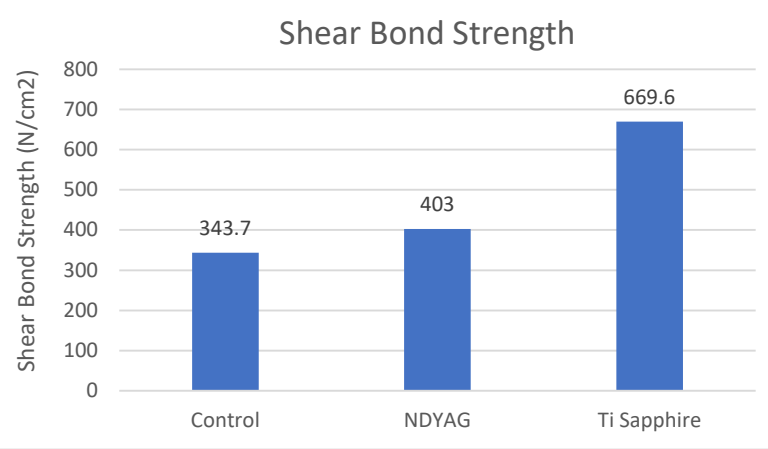

Figure 7. Graphical Representation of Mean Shear Bond Strength.

energy has the least deleterious impact and deserves further evaluation. The surface treatment of Y-TZP is done to increase the surface roughness at the microscopic level achieving high surface energy and enhanced wetting ability. ${ }^{19}$

In this study, the Nd: YAG laser is used, generating a light beam in the near-infrared region of the electromagnetic spectrum at $1064 \mathrm{~nm}$. The primary property of laser energy is the transformation of light into heat. The $\mathrm{Nd}$ : YAG laser operates in both pulse and continuous modes. The pulse mode can further be long-pulse (minimum pulse width of 10 milliseconds) and Q Switched dual pulse mode (minimum pulse width of 5-10 nanoseconds).

In this study, the Nd: YAG laser in $\mathrm{Q}$ switched dual pulse mode is used because of its short pulse width and high peak power for surface treatment on zirconia core discs with minimal collateral thermal damage, and it produces selective photo thermo-lysis. ${ }^{20}$ In this study, the laser surface treatment of zirconia core discs was done after sintering (post-sintered). Spohr et $\mathrm{al}^{21}$ and Akyil et $\mathrm{a}^{22}$ studied the effect of this laser on post-sintered zirconia, whereas Kirmali et al. ${ }^{3,23,24}$ evaluated its effect on pre-sintered zirconia.

Ebeid et $\mathrm{al}^{25}$ assessed surface treatment on pre- and post-sintered zirconia and found increased surface roughness and bond strength in the post-sintered group. Kurtulmus et $\mathrm{al}^{16}$ studied the phase transformation of zirconia after surface treatment before and after sintering. They observed increased monoclinic phase content in the post-sintered group by X-ray diffraction analysis. They concluded that there is reverse phase transformation (monoclinic to tetragonal) of zirconia after thermal treatment, and temperature simulates the firing of the veneer.

Usumuz et $\mathrm{al}^{15}$ noticed the enhanced surface roughness of zirconia with short pulse duration (180 microseconds) when compared with long pulse duration (320 microseconds). The reduction in pulse duration caused an increase in the peak power of the laser beam and this caused higher surface roughness and bond strength.

Liu et $\mathrm{al}^{26}$ studied the outcome of the Nd: YAG laser on the zirconia ceramic by altering output power $(1 \mathrm{~W}, 2 \mathrm{~W}$, $3 \mathrm{~W}$ ) and irradiation time (30, 60 and 90 seconds). An increase in output power or irradiation time was supposed to enhance the bond strength of the ceramic but the effect was opposite in this study. The irradiation time for the current study is kept at 30 seconds in accordance with that study. Air and water cooling were not used because water causes increased material deterioration as it acts as a medium for laser energy absorption and produces lower bond strength. ${ }^{14}$ The release of energy causes conditioning on the coated surface, while removing graphite as the zirconia surface is scanned with the fiber-optic tip. ${ }^{14}$

The result of this study can be explained by the fact that Laser causes pinpoint micro-explosions at the surface of zirconia leading to increased surface roughness. The high peak power and ultra-short pulse width (5-10 nanoseconds) causes increased shear bond strength of zirconia. This is in concurrence with the works done by Usumuz et $\mathrm{al}^{15}$ and Liu et al. ${ }^{26}$ The result of my study does not match with the study done by Akyil et al. ${ }^{22}$ because of air and water cooling.

Erdur and Basciftci ${ }^{27}$ assessed the consequence of the Ti: sapphire laser rendering a more homogeneous ablation pattern on the feldspathic porcelain surface in comparison with Er: YAG and Nd: YAG with the highest shear bond strength between the ceramic surface and the orthodontic bracket. Kara et al found that the femtosecond laser showed higher surface roughness on zirconia in comparison with Nd: YAG and Er: YAG. It showed increased bonding of resin cement and zirconia. ${ }^{28}$ The Titanium sapphire laser is a highly powerful and ultrafast laser that imparts the laser beam for picoseconds and femtosecond pulse width and causes no collateral thermal damage. The femtosecond laser seems to be a proper method for a zirconia surface modification as it did not increase the monoclinic content of zirconia evaluated with X-ray diffraction analysis. ${ }^{29}$ The null hypothesis is not accepted; thus, "there is a significant difference noted in mean shear bond strengths at the zirconia-veneering ceramic juncture between group $\mathrm{C}$, group $\mathrm{N}$ and group T". The alternate hypothesis is accepted.

The constraints of the work are as follows: the shape of the specimen did not resemble that of clinical restoration and the influence of aging and thermo-cycling ${ }^{30}$ on the bonding potential of zirconia and veneering ceramics was not assessed. This study did not evaluate the effect of other lasers like carbon dioxide and Erbium: yttrium aluminum garnet. Therefore, further studies are needed.

\section{Conclusion}

After statistical analysis and thorough discussion, the following inference was made in the present study:

The titanium sapphire laser shows the highest shear bond strength at the time duration of 30 seconds. It is a promising mode of surface treatment of post-sintered 
zirconia to increase the shear bond at the zirconia coreveneer ceramic juncture.

\section{Acknowledgements}

This is an original research work with no prior publication conducted by Government college of dentistry, Indore with the technical support of Raja Ramanna Centre for Advanced Technology (RRCAT), Indore. The authors take responsibility of the contents presented here in terms of accuracy of data and citing resources. This work was not supported by any monetary funding or grant.

\section{Ethical considerations}

Approval from ethical committee was received prior to the study (Approval No. 062/IEC/SS/2017).

\section{Conflict of Interests}

The authors acknowledge all participants with no conflict of interest.

\section{Reference}

1. Gautam C, Joyner J, Gautam A, Rao J, Vajtai R. Zirconia based dental ceramics: structure, mechanical properties, biocompatibility and applications. Dalton Trans. 2016; 45(48):19194-19215. Doi: 10.1039/c6dt03484e

2. Tinschert J, Zwez D, Marx R, Anusavice KJ. Structural reliability of alumina-, feldspar-, leucite-, mica-and zirconia-based ceramics. J Dent. 2000; 28(7):529-35. Doi: 10.1016/s0300-5712(00)00030-0

3. Kirmali O, Kapdan A, Kustarci A, Er K. Veneer ceramic to Y-TZP bonding: comparison of different surface treatments. J Prosthodont. 2016; 25(4):324-9. Doi: 10.1111/ jopr.12304

4. Teng J, Wang H, Liao Y, Liang X. Evaluation of a conditioning method to improve core-veneer bond strength of zirconia restorations. J Prosthet Dent. 2012; 107(6):380-7. Doi: 10.1016/S0022-3913(12)60095-X

5. de Mello CC, Bitencourt SB, dos Santos DM, Pesqueira AA, Pellizzer EP, Goiato MC. The effect of surface treatment on shear bond strength between Y-TZP and veneer ceramic: A systematic review and meta-analysis. J Prosthodont. 2018; 27(7):624-635. Doi: 10.1111/jopr.12727

6. Kunt GE, Duran I. Effects of laser treatments on surface roughness of zirconium oxide ceramics. BMC Oral Health. 2018; 18(1):1-7. Doi: 10.1186/s12903-018-0688-y

7. Martins FV, Mattos CT, Cordeiro WJ, Fonseca EM. Evaluation of zirconia surface roughness after aluminum oxide airborne-particle abrasion and the erbium-YAG, neodymium-doped YAG, or CO2 lasers: A systematic review and meta-analysis. J Prosthet Dent. 2019; 121(6):895903. Doi: 10.1016/j.prosdent.2018.07.001

8. Arami S, Tabatabae MH, Namdar SF, Chiniforush N. Effects of different lasers and particle abrasion on surface characteristics of zirconia ceramics. J Dent (Tehran). 2014; 11(2):233-41. Epub 2014 Mar 31

9. Maziero Volpato CA, Carvalho O, Özcan M, Fredel MC, Silva FS. Effect of laser irradiation on the adhesion of resinbased materials to zirconia: a systematic review and metaanalysis. J Adhesion Sci Tech. 2021;35(10):1035-56. Doi:
10.1080/01694243.2020.1834287

10. Mirhashemi A, Sharifi N, Moharrami M, Chiniforush $\mathrm{N}$. Evaluation of different types of lasers in surface conditioning of porcelains: A review article. J Lasers Med Sci. 2017;8(3):101-11. Doi: 10.15171/jlms.2017.19.

11. Šulc J, Jelínková H. Lasers for Medical Applications. In: Jelínková $\mathrm{H}$, ed. Solid-state lasers for medical applications. Woodhead publishing; 2013:127-176. Doi: 10.1533/9780857097545.2.127

12. Serbin J, Bauer T, Fallnich C, Kasenbacher A, Arnold WH. Femtosecond lasers as novel tool in dental surgery. Applied Surf Sci. 2002; 197-8:737-40. Doi: 10.1016/S01694332(02)00402-6

13. Guess PC, Kuliš A, Witkowski S, Wolkewitz M, Zhang Y, Strub JR. Shear bond strengths between different zirconia cores and veneering ceramics and their susceptibility to thermocycling. Dent Mater. 2008; 24(11):1556-67. Doi: 10.1016/j.dental.2008.03.028

14. Al-Dohan HM, Yaman P, Dennison JB, Razzoog ME, Lang BR. Shear strength of core-veneer interface in bilayered ceramics. J Prosthet Dent. 2004; 91(4):349-55. Doi: 10.1016/j.prosdent.2004.02.009

15. Usumez A, Hamdemirci N, Koroglu BY, Simsek I, Parlar O, Sari T. Bond strength of resin cement to zirconia ceramic with different surface treatments. Lasers Med Sci. 2013;28(1):259-66. Doi: 10.1007/s10103-012-1136-x

16. Kurtulmus-Yilmaz S, Aktore H. Effect of the application of surface treatments before and after sintering on the flexural strength, phase transformation and surface topography of zirconia. J Dent. 2018; 72:29-38. Doi: 10.1016/j. jdent.2018.02.006

17. Siviloglou GA, Christodoulides DN. Accelerating finite energy Airy beams. Opt Lett. 2007; 32(8):979-81. Doi: 10.1364/ol.32.000979

18. Daskalova A, Angelova L, Carvalho A, Trifonov A, Nathala C, Monteiro F, Buchvarov I. Effect of surface modification by femtosecond laser on zirconia based ceramics for screening of cell-surface interaction. Applied Surf Sci. 2020; 513:145914. Doi: 10.1016/j.apsusc.2020.145914

19. Ruja MA, De Souza GM, Finer Y. Ultrashort-pulse laser as a surface treatment for bonding between zirconia and resin cement. Dent Mater. 2019; 35(11):1545-56. Doi: 10.1016/j. dental.2019.07.009

20. Henriques B, Hammes N, Souza JC, Özcan M, MesquitaGuimarães J, Silva FS, Fredel MC, Volpato CM, Carvalho Ó. Influence of ns-Nd: YAG laser surface treatment on the tensile bond strength of zirconia to resin-matrix cements. Ceram Int. 2020; 46(17):27822-31. Doi: 10.1016/j. ceramint.2020.07.281

21. Spohr AM, Borges GA, Júnior LH, Mota EG, Oshima HM. Surface modification of In-Ceram Zirconia ceramic by Nd: YAG laser, Rocatec system, or aluminum oxide sandblasting and its bond strength to a resin cement. Photomed Laser Surg. 2008; 26(3):203-8. Doi: 10.1089/pho.2007.2130

22. Akyıl MŞ, Uzun İH, Bayındır F. Bond strength of resin cement to yttrium-stabilized tetragonal zirconia ceramic treated with air abrasion, silica coating, and laser irradiation. Photomed Laser Surg. 2010; 28(6):801-8. Doi: 10.1089/pho.2009.2697

23. Kirmali O, Akin H, Ozdemir AK. Shear bond strength of 
veneering ceramic to zirconia core after different surface treatments. Photomed Laser Surg. 2013; 31(6):261-8. Doi: 10.1089/pho.2013.3487

24. Kirmali O, Kustarci A, Kapdan A, Er K. Efficacy of surface roughness and bond strength of Y-TZP zirconia after various pre-treatments. Photomed Laser Surg. 2015; 33(1):15-21. Doi: 10.1089/pho.2014.3825

25. Ebeid K, Wille S, Salah T, Wahsh M, Zohdy M, Kern M Evaluation of surface treatments of monolithic zirconia in different sintering stages. J Prosthodont Res. 2018;62(2):2107. Doi: 10.1016/j.jpor.2017.09.001

26. Liu L, Liu S, Song X, Zhu Q, Zhang W. Effect of Nd: YAG laser irradiation on surface properties and bond strength of zirconia ceramics. Lasers Med Sci. 2015; 30(2):627-34. Doi: 10.1007/s10103-013-1381-7

27. Erdur EA, Basciftci FA. Effect of Ti: sapphire laser on shear bond strength of orthodontic brackets to ceramic surfaces. Lasers Surg Med. 2015; 47(6):512-9. Doi: 10.1002/ $1 \mathrm{sm} .22371$

28. Kara O, Kara HB, Tobi ES, Ozturk AN, Kilic HS. Effect of various lasers on the bond strength of two zirconia ceramics. Photomed Laser Surg. 2015; 33(2):69-76. Doi: 10.1089/pho.2014.3841

29. Aivazi M, hossein Fathi M, Nejatidanesh F, Mortazavi V, HashemiBeni B, Matinlinna JP, Savabi O. The evaluation of prepared microgroove pattern by femtosecond laser on alumina-zirconia nano-composite for endosseous dental implant application. Lasers Med Sci. 2016; 31(9):1837-43. Doi: 10.1007/s10103-016-2059-8

30. Juntavee N, Serirojanakul P. Influence of different veneering techniques and thermal tempering on flexural strength of ceramic veneered yttria partially stabilized tetragonal zirconia polycrystalline restoration. J Clin Exp Dent. 2019; 11(5): e421-e431. Doi: 10.4317/jced.5572 